\title{
Dye-Sensitized Solar Cells: A Successful Combination of Materials
}

\author{
Claudia Longo and Marco-A. De Paoli* \\ Instituto de Química, Universidade Estadual de Campinas, CP 6154, 13084-971 Campinas - SP, Brazil
}

\begin{abstract}
As células solares de $\mathrm{TiO}_{2}$ /corante são uma alternativa promissora para o desenvolvimento de uma nova geração de dispositivos fotovoltaicos. Estas células resultam de uma bem sucedida combinação de materiais: um eletrodo transparente revestido com um filme poroso de partículas nanocristalinas de $\mathrm{TiO}_{2}$ sensibilizadas com um corante, um eletrólito contendo um par redox adequado e um contra-eletrodo revestido com platina. Em geral, utilizam-se complexos bipiridínicos de Ru como corantes fotosensibilizadores. O desempenho da célula na conversão de luz em eletricidade depende dos níveis de energia do semicondutor e do corante, e da cinética dos processos de transferência de elétrons na interface semicondutor | eletrólito. Esta revisão apresenta uma discussão da influência de cada um dos materiais que constituem as células solares de $\mathrm{TiO}_{2}$ /corante no processo de conversão de energia, com ênfase aos resultados obtidos para células solares de estado sólido, preparadas com um eletrólito polimérico.
\end{abstract}

Dye-sensitized $\mathrm{TiO}_{2}$ solar cells, DSSC, are a promising alternative for the development of a new generation of photovoltaic devices. DSSC are a successful combination of materials, consisting of a transparent electrode coated with a dye-sensitized mesoporous film of nanocrystalline particles of $\mathrm{TiO}_{2}$, an electrolyte containing a suitable redox-couple and a Pt coated counter-electrode. In general, Ru bipyridyl complexes are used as the dye sensitizers. The light-to-energy conversion performance of the cell depends on the relative energy levels of the semiconductor and dye and on the kinetics of the electron-transfer processes at the sensitized semiconductor | electrolyte interface. The rate of these processes depends on the properties of its components. This contribution presents a discussion on the influence of each of the materials which constitute the DSSC of the overall process for energy conversion. An overview of the results obtained for solid-state dye-sensitized $\mathrm{TiO}_{2}$ solar cells assembled with polymer electrolytes is also presented.

Keywords: energy conversion, dye solar cells, solid-state dye solar cells, polymer electrolyte

\section{Introduction}

Several interests have motivated the development of alternative energy sources, including those related to economical and political questions, as well as those related to health and environmental concerns, e.g., for decreasing air pollution and carbon dioxide emission. In view of such concerns, solar energy can be considered the most important energy source: it is abundant, clean, safe, and allows energy generation in remote areas. ${ }^{1,2}$

Solar energy conversion and storage can be achieved by photo-electrochemical processes, and photosynthesis is the most successful example of this approach. A strategy for chemically-based solar energy conversion is semiconductor | liquid junction solar cells, for instance $n$-CdSe in aqueous $\mathrm{Fe}(\mathrm{CN})_{6}^{3-14-}$ or poly-chalcogenides

\footnotetext{
* e-mail: mdepaoli@iqm.unicamp.br
}

(Figure 1). When illuminated, the semiconductor collects photons with energy that exceeds the energy gap between the valence and the conduction bands. It promotes the

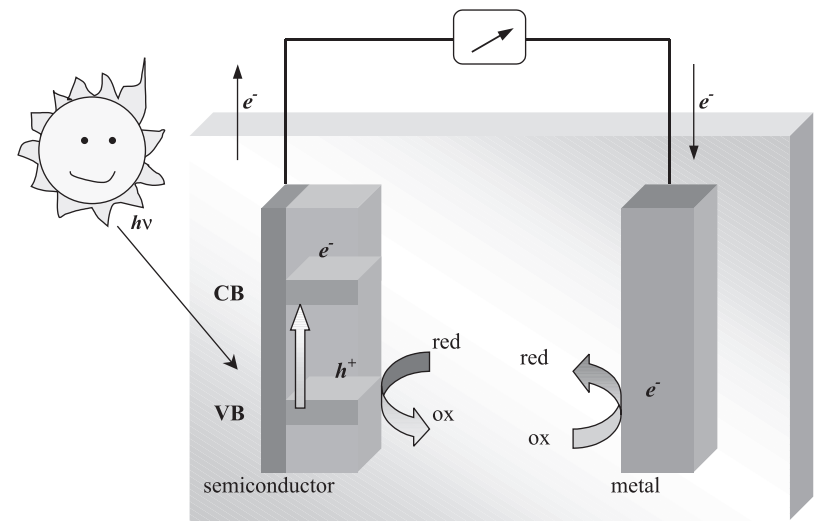

Figure 1. Representation of a semiconductor | liquid junction photovoltaic cell. 
separation of electron/hole pairs, i.e., an electron is promoted from the valence band (VB) to the conduction band (CB), leaving behind a hole, a positively charged VB vacancy. While the electron moves away from the interface and toward the external circuit, the hole migrates to the semiconductor $\mid$ solution interface. At the interface, the hole oxidizes an electron donor in solution. The oxidized molecule diffuses through solution to the counterelectrode, where it can be reduced, completing the circuit. Thus, only electricity is produced and no net chemical reaction occurs since every interfacial oxidation at the photoelectrode is compensated by an interfacial reduction reaction at the counter-electrode. Direct energy conversion relies on the semiconductor material, which can absorb a fraction of the solar spectrum depending on its bandgap energy $\left(\mathrm{E}_{\mathrm{bg}}\right)$. Unfortunately, many materials with adequate bandgaps are susceptible to photocorrosion, due to destructive hole-based reactions. Also, the semiconductors less susceptible to photocorrosion, such as metal oxides like $\mathrm{TiO}_{2}$ and $\mathrm{SnO}_{2}$, exhibit a too large bandgap to permit significant collection of visible light., ${ }^{2,3}$

An alternative to overcome the limited spectral sensitivity of the wide band-gap semiconductors, which are restricted to UV light, is surface modification with visible-light absorbing dye molecules. The sensitization of semiconductors using dyes is a century old, when it was used in the development of photography. ${ }^{2-4}$ Their application in solar energy conversion is more recent, and progressed considerably after the seventies, with the advances in the development of dye sensitizers, especially bipyridyl $\mathrm{Ru}$ complexes with anchoring groups to attach them to the semiconductor surface. ${ }^{2-4}$

Photoelectrochemical cells based on dye-sensitized semiconductor electrodes also include solutions containing a suitable redox couple and a counter-electrode. The illumination leads to excitation of the dye to an electronically excited state which is quenched by electrontransfer to the $\mathrm{CB}$ of the semiconductor, leaving the dye in an oxidized state. The oxidized dye is reduced by the electron donor present in the electrolyte. The electrons in the $\mathrm{CB}$ are collected, flow through the external circuit to arrive at the counter-electrode, where they cause the reverse reaction of the redox mediator. Thus, the photoelectrochemical cell is also regenerative and the process leads to direct conversion of sunlight into electricity. If only the above reactions took place, the solar cell would be stable, delivering photocurrent indefinitely. The maximum photovoltage, at open circuit potential $\left(\mathrm{V}_{\mathrm{OC}}\right)$, is the difference between the Fermi level (CB) of the semiconductor under illumination and the redox potential of the mediating redox couple. The photocurrent yield depends on the spectral and redox properties of the dye, its excited state lifetimes, the efficiency of charge injection, the ionic conductivity of the electrolyte and the properties of the semiconductor electrode to collect and channel the electrons through the external circuit. ${ }^{3,4}$

\section{Nanocrystalline Dye-Sensitized $\mathrm{TiO}_{2}$ Solar Cells}

In earlier studies of photoelectrochemical cells, just single crystals or flat electrodes of polycrystalline films of tin oxide or titanium oxide were used. In spite of the efficient electron injection into the semiconductor, the light harvesting efficiency was very small and the efficiencies of the solar cells were extremely low, below $1 \% .^{2,4,6}$ At the beginning of the nineties, in the laboratories of Grätzel, in Lausanne, Switzerland, the planar semiconductor electrode was replaced by a porous film of nanocrystalline $\mathrm{TiO}_{2}$ particles deposited onto a conducting glass electrode. The enormous surface area of the nanocrystalline $\mathrm{TiO}_{2}$ film allowed high light harvesting efficiency and the overall efficiency for solar energy conversion increased by an order of magnitude.,4-8 The regenerative dye-sensitized $\mathrm{TiO}_{2}$ photoelectrochemical cell attracted the attention of several researchers. A photoelectrochemical cell was patented by Grätzel in 1990 (US Patent 4,927,721) and, after that, more than 800 patents were registered at The United States Patent and Trademark Office. ${ }^{9}$ A schematic representation of a nanocrystalline dye-sensitized $\mathrm{TiO}_{2}$ solar cell, DSSC, and the processes that occur during cell operation are depicted in Figure 2.

The efficiency of a DSSC in the process for energy conversion depends on the relative energy levels and the kinetics of electron transfer processes at the liquid junction of the sensitized semiconductor | electrolyte interface. For efficient operation of the cell, the rate of electron injection must be faster than the decay of the dye excited state. Also, the rate of re-reduction of the oxidized sensitizer (or dye cation) by the electron donor in the electrolyte (Figure 2, equation 4) must be higher than the rate of back reaction of the injected electrons with the dye cation (Figure 2, equation 3 ), as well as the rate of reaction of injected electrons with the electron acceptor in the electrolyte (Figure 2, equation 6). Finally, the kinetics of the reaction at the counter-electrode must also guarantee the fast regeneration of charge mediator (Figure 2, equation 5), or this reaction could also become rate limiting in the overall cell performance. ${ }^{4-8}$

The most efficient DSSC that has been reported consisted of a porous anatase $\mathrm{TiO}_{2}$ film, deposited onto a transparent electrode, sensitized by the dye $\mathrm{Ru}^{\mathrm{II}}\left(2,2^{2}-\right.$ 


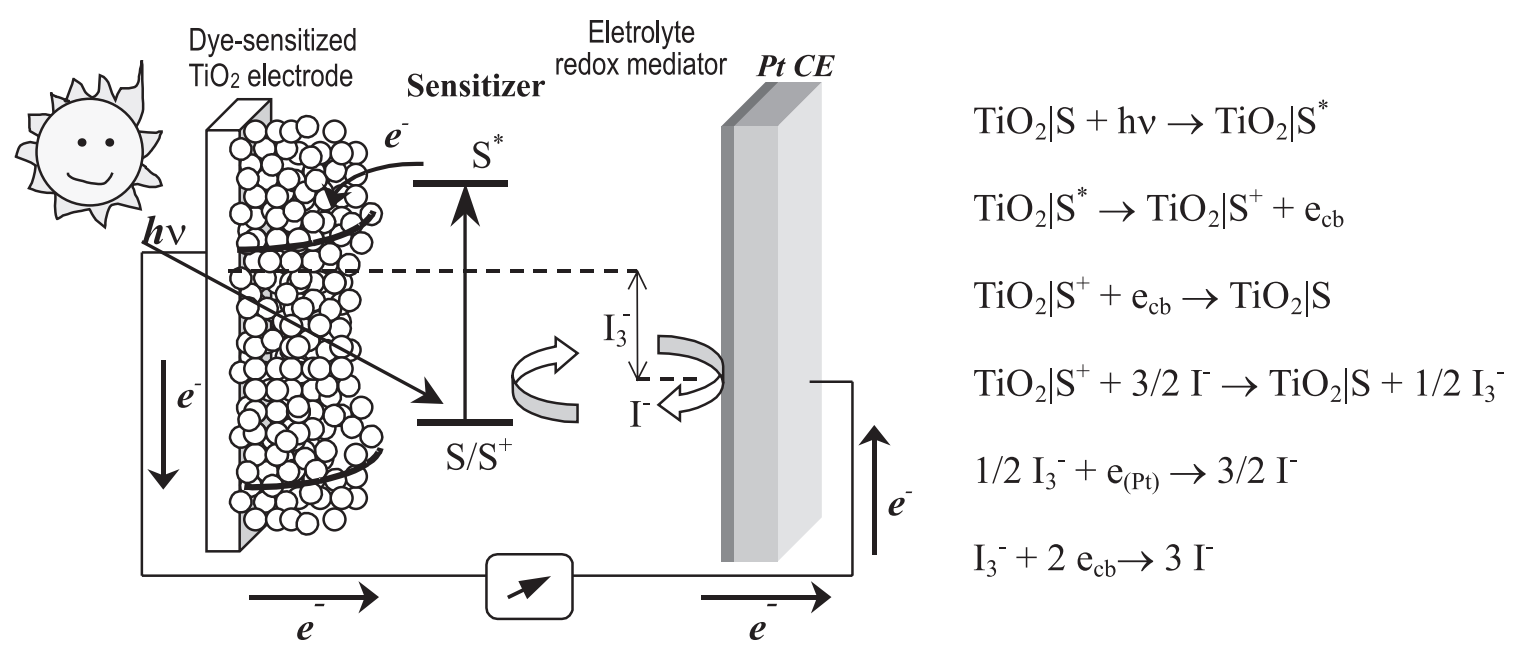

Figure 2. Representation of a dye-sensitized $\mathrm{TiO}_{2}$ solar cell and the processes involved in energy conversion ( $\mathrm{S}$ represents the dye-sensitizer and $\mathrm{I}^{-} / \mathrm{I}_{3}^{-}$is the charge mediator).

bipyridyl-4,4'-dicarboxylate) ${ }_{2}$-(NCS) ${ }_{2}$ (also called N3 dye), an acetonitrile electrolyte with the redox couple $\mathrm{I}^{-} / \mathrm{I}_{3}^{-}$and a Pt counter-electrode, as represented in Figure 2. The photocurrent measured at $c a .100 \mathrm{~mW} \mathrm{~cm}{ }^{-2}$ of simulated solar intensity (AM 1.5) was $20 \mathrm{~mA} \mathrm{~cm}^{-2}$, the open circuit voltage, $\mathrm{V}_{\mathrm{OC}}$, was $\sim 0.7 \mathrm{~V}$, and the overall efficiency of the cell for light to electrical conversion was $\eta_{\text {global }} \sim 10 \%$. The cell performance was still better under diffuse daylight, $\eta_{\text {global }} \sim 12 \%$, revealing that the DSSC is less sensitive to light intensity variations than conventional photovoltaic devices, which is an important advantage for application in consumer electronic devices. ${ }^{4-8,10}$

For the DSSC based on Ru bipyridyl complexes and nanocrystalline $\mathrm{TiO}_{2}$, the charge injection is a very fast process, usually in the femtosecond time domain. On the other hand, the recombination, or electron back reaction (Figure 2, equation 3) is much slower, and occur over a much longer time scale (several microseconds or longer). This difference of several orders of magnitude for the forward and reverse electron transfer rates allows the efficient processing of the charge separated products, i.e., the reduction of the dye cation by iodide and the percolation of the injected electrons in the $\mathrm{TiO}_{2}$ film to arrive at the back contact. ${ }^{4,7}$

The rate for dye regeneration reaction (Figure 2, equation 4) is very important for the efficiency of the cell, since it affects the electron collection efficiency, i.e., the relative amount of electrons that leave the semiconductor and contribute to the photocurrent. Considering some experimental evidence, the suggested mechanism for rereduction of the oxidized dye by iodide involves the formation of $\mathrm{I}_{2}{ }^{-}$radical on the surface of the oxide, followed by a disproportionation, as shown in reactions $4 \mathrm{a}$ and $4 \mathrm{~b}$. This pathway can be preferred if iodide ions were adsorbed on the surface, which depends on the nature and concentration of the cations in electrolyte. ${ }^{11}$

$\mathrm{TiO}_{2}\left|\mathrm{~S}^{+}+2 \mathrm{I}^{-} \rightarrow \mathrm{TiO}_{2}\right| \mathrm{S}+\mathrm{I}_{2}^{--}$

$2 \mathrm{I}_{2}^{-{ }^{-}} \rightarrow \mathrm{I}^{-}+\mathrm{I}_{3}^{-}$

The electron percolation, i.e., the process by which the injected electrons hop through the colloidal oxide particles and arrive at the collector (the conducting glass electrode), appears to take place by diffusion. The values for the electron diffusion coefficient were estimated as $c a \cdot 10^{-4}$ $\mathrm{cm}^{2} \mathrm{~s}^{-1}$, which is more than two orders of magnitude lower than those estimated for bulk anatase., ${ }^{4,12}$ The injected electrons can also react with triiodide (Figure 2, equation $6)$. This probably occurs via traps and intermediate reactions. This reaction, also called "dark current", is the main loss mechanism for the DSSC. ${ }^{4}$

Since the nanocrystalline DSSC consisted of a combination of several inorganic materials, as illustrated in Figure 3, the properties of its components can influence the kinetics of the indicated reactions and, consequently, the performance of the cell. Thus, the cell conversion performance depends on the structure, morphology, optical and electrical properties of the porous semiconductor film; the chemical, electrochemical, photophysical and photochemical properties of the dye; the electrochemical and optical properties of the redox couple and the solvent in the electrolyte; and the electrochemical properties of the counter-electrode. ${ }^{4}$ The following sections will discuss some characteristics of each of the components which 
constitute the DSSC, and how they can influence the processes for energy conversion.

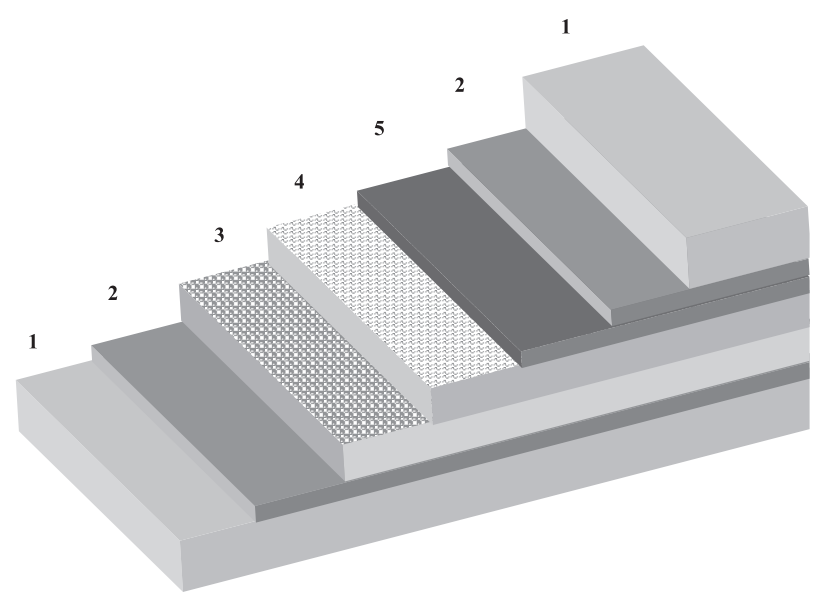

Figure 3. Schematic representation of the materials, which constitute a dye-sensitized $\mathrm{TiO}_{2}$ solar cell. (1) Insulating and transparent substrate (glass or PET); (2) Transparent conducting layer (FTO or ITO); (3) Dye-sensitised nanocrystalline semiconductor; (4) Electrolyte; (5) Pt film.

\subsection{The porous nanocrystalline semiconductor film, a metal oxide}

In general, the porous semiconductor film consists of a large collection of nano-sized particles of a metal oxide interconnected by meso-sized pores, deposited onto the conductive surface of a transparent electrode. This porous metal oxide film acts as a high surface area support for the sensitizer, a pathway for electrical current and a porous membrane for diffusion of the redox couple. ${ }^{7}$

The first requisite for application of a semiconductor in a DSSC is related to the relative energy levels at the semiconductor $\mid$ sensitizer interface. The position of the $\mathrm{CB}$ edge of the semiconductor must allow charge injection from the excited-state of the dye. If this first condition is accomplished, morphological and structural characteristics of the semiconductor film also play a very important role in the processes for solar cell operation. ${ }^{3-6}$ The semiconductor nanoparticles exhibit a large number of traps, i.e., band gap localized states. The occupancy of such surface states, which can present distinct Fermi levels, may also affect the kinetics for charge transfer and recombination at the semiconductor | electrolyte interface. ${ }^{13}$

As mentioned before, the high surface area of the nanocrystalline $\mathrm{TiO}_{2}$ film plays a crucial role for increasing the performance of the photoelectrochemical cell in energy conversion. For a planar electrode, light harvesting is poor due to the small absorption cross section of a monolayer of the dye. In highly porous films of a few micrometers thickness, the available surface area for dye absorption can be enormous, leading to near extinction of incident light. ${ }^{4}$ A suitable degree of porosity is another important factor too. To guarantee the regeneration of the oxidized dye, the structure of the pores must permit the penetration of the electrolyte containing the redox couple, and permit an effective mass transport of electroactive species by diffusion. ${ }^{14}$ Furthermore, the porous film must exhibit interconnected particles, to allow the percolation of injected electrons. The crystallinity of the particles (and the extent of defects) also influences the injection of electrons and their transport through the network of particles in the film. ${ }^{4,8}$ As stated by Grätzel, "a desirable morphology of the films would have mesoporous channels aligned in parallel to each other and vertically aligned with respect to the transparent glass current collector electrode". ${ }^{8}$ Also, as previously discussed, the main loss mechanism in a nanocrystalline $\mathrm{TiO}_{2} \mathrm{DSSC}$ is the reaction of injected electrons with triiodide (Figure 2, equation 6). Since increasing the film thickness also increases the probability for dark current, there is an optimal $\mathrm{TiO}_{2}$ film thickness in which the cell produces the maximum photocurrent. $^{4}$

The oxide semiconductor most used in DSSC is $\mathrm{TiO}_{2}$ in the anatase crystalline form. Other semiconducting oxides, like $\mathrm{ZnO}$ and $\mathrm{SnO}_{2}$, have also been used in DSSC, but the cells exhibited lower performances in comparison to cells prepared with $\mathrm{TiO}_{2}$. The $\mathrm{TiO}_{2}$ is a wide bandgap semiconductor, $\mathrm{E}_{\mathrm{bg}} \sim 3.2 \mathrm{eV}$. It is a non-toxic and inert compound, an inexpensive and readily available material. Thin porous films of $\mathrm{TiO}_{2}$ particles can be prepared by different techniques, and two of them are the more usual for application in DSSC. ${ }^{4,6}$

An easy and very common method utilizes commercially available $\mathrm{TiO}_{2}$ power, Degussa $P$-25, for preparing a viscous aqueous suspension which also includes components such as acetylacetone and a surfactant, e.g., Triton X-100. The suspension can be spread onto the transparent electrode with a glass rod, using adhesive tape for controlling the thickness of the film, and the electrode is heated to $450{ }^{\circ} \mathrm{C}$ for $30 \mathrm{~min}$. This thermal treatment produces electronic contacts not only between the particles and the support but also between all the particles of the film. ${ }^{10}$ The thermal treatment also eliminates contamination by residues of organic compounds present in the suspensions used to prepare the film. Another method widely used for manufacturing DSSC involves the preparation of a colloidal suspension of $\mathrm{TiO}_{2}$ by hydrolysis of Ti-isopropoxide with nitric or acetic acid. After steps of peptization and hydrothermal growth of the particles by 
autoclaving, and addition of PEG 20000 as a binder, a film of the suspension can be spread onto the transparent electrode by the same procedure as described above. ${ }^{15}$ Usually, DSSC assembled with $\mathrm{TiO}_{2}$ photoelectrodes prepared by the latter method exhibit better performance than cells assembled with electrodes obtained by the former one. Lately, some better results were reported for DSSC prepared with the Degussa $P-25 \mathrm{TiO}_{2}$ powder by using a method which includes a prior treatment of the powder with nitric acid and the addition of PEG 20000 and a cellulosic polymer to the suspension. ${ }^{16}$

Recently, the preparation of $\mathrm{TiO}_{2}$ films by DC magnetron sputtering for application in DSSC was also reported. ${ }^{17}$ The high efficiency of the cells $\left(\eta_{\text {global }} \sim 7 \%\right)$ was attributed to the columnar structure of the $\mathrm{TiO}_{2}$ film, with a large internal surface area and electrical contiguity over the full cross section of the film. This methodology can be considered very interesting, since the DC magnetron sputtering technique has industrial viability. ${ }^{17}$

Methods for modification of $\mathrm{TiO}_{2}$ properties have also been investigated. Considering that the dark current due to reaction of injected electrons with triiodide (Figure 2, equation 6) is the main loss mechanism in DSSC, the literature reports several attempts to minimize this reaction. One approach consists in enhancement of electrical conductivity in the $\mathrm{TiO}_{2}$ film to increase the rate for electron percolation through the film. For this purpose, single-wall carbon nanotubes (CNT) were incorporated in $\mathrm{TiO}_{2}$ films and their effects on the performance of DSSC were investigated. DSSC cells prepared with CNT modified $\mathrm{TiO}_{2}$ electrodes exhibited higher photocurrents than those with non-modified ones, however, contrary to the initial prospect, an increase in the dark current was also observed. ${ }^{18}$ Another approach involves a blocking of the surface by the formation of an insulating layer or an energy barrier that allows electron injection from the dye but can reduce the recombination reaction. Such barriers can be made by coating the $\mathrm{TiO}_{2}$ with semiconductors that have a more negative conduction band, e.g., $\mathrm{Nb}_{2} \mathrm{O}_{5}$ or $\mathrm{SrTiO}_{3}$. With these modified $\mathrm{TiO}_{2}$ films, the DSSC exhibited lower dark currents and an enhanced overall efficiency in comparison to similar cells assembled with non-modified $\mathrm{TiO}_{2}$ films. ${ }^{19}$

The properties of porous $\mathrm{TiO}_{2}$ films also depend on the characteristics of the transparent electrode used as substrate. Usually, the $\mathrm{TiO}_{2}$ film is deposited on glass electrodes coated with a thin conductive layer of fluorinedoped tin oxide (FTO) or tin-doped indium oxide (ITO). These electrodes are quite transparent in the visible region and presented sheet resistivity of $10-20 \Omega \mathrm{cm}^{-2}$. However, the resistivity of glass-ITO electrodes can increase considerably after thermal treatment, which causes an increase in the series resistance in the DSSC, decreasing its performance. Since this effect is not observed when glass-FTO electrodes are heated to such temperatures, transparent electrodes based on FTO are more adequate for application in DSSC than ITO electrodes. Both glassITO and glass-FTO electrodes are commercially available. However, transparent electrodes based on tin oxide thin films doped with $\mathrm{F}$ or $\mathrm{Sb}$ can be easily prepared by the Spray Pyrolysis technique, which consists in spraying over heated glass a methanol solution of $\mathrm{SnCl}_{4}$ (or other precursor) containing the appropriate dopant. ${ }^{20}$

Recently, attempts to lower the costs and broaden the applicability of the DSSC led to the use of flexible polymer electrodes. Flexible electrodes, like the films of poly(ethylene terephthalate) coated with tin-doped indium oxide (PET-ITO), present lower cost and some technological advantages relative to glass-ITO electrodes, e.g., lower weight, higher impact resistance and less form and shape limitations. For these reasons, interest in its use for assembling $\mathrm{TiO}_{2} /$ dye-based photoelectrochemical devices has increased. ${ }^{21-26}$ Deposition of nanoparticulated $\mathrm{TiO}_{2}$ on PET-ITO is difficult, however, because the thermal treatment has to be limited to $150{ }^{\circ} \mathrm{C}$, reducing adhesion, electrical contact between the particles and adsorption of the dye. Also, the low temperature precludes total elimination of organic residues from the surfactants commonly used in $\mathrm{TiO}_{2}$ suspensions. A very successful alternative method for preparation of a porous semiconductor film at low temperatures was achieved by depositing a film of Degussa $P-25 \mathrm{TiO}_{2}$ particles dispersed in ethanol followed by compressing the films at pressures of $1500 \mathrm{~kg} \mathrm{~cm}^{-1}$ for few seconds. The DSSC prepared with such electrodes (active area of $0.32 \mathrm{~cm}^{2}$ ) exhibited efficiencies of $4-5 \%$. However, their stability was poor, which was associated with the water permeability of the flexible electrodes. ${ }^{23}$

Another alternative to make flexible DSSC consists of depositing a film of $\mathrm{TiO}_{2}$ particles onto flexible electrodes from the usual suspension, exposing the film to UV radiation for few minutes and heating them at $140-150{ }^{\circ} \mathrm{C} .{ }^{26}$ This treatment promotes the photodegradation of organic compounds, allowing the elimination of most of the organic residues from the $\mathrm{TiO}_{2}$ suspension. The resulting films were mechanically stable, presented an intense adsorption of the dye and relatively good performance in solid-state, flexible $\mathrm{TiO}_{2}$ /dye solar cells assembled with a polymer electrolyte. These cells, with an active area of $1 \mathrm{~cm}^{2}$, exhibited short-circuit current $\mathrm{I}_{\mathrm{SC}}=60 \mu \mathrm{A} \mathrm{cm}^{-2}$, open circuit potential $\mathrm{V}_{\mathrm{OC}}=0.7 \mathrm{~V}$ and $\eta_{\text {global }}=0.32 \%$ under $10 \mathrm{~mW} \mathrm{~cm}^{-2}\left(\eta_{\text {global }}=0.23 \%\right.$ under $\left.100 \mathrm{~mW} \mathrm{~cm}^{-2}\right)$. The efficiency of these cells also decayed with time, but cell 
performance loss was associated with an increase in the series resistance of the cell, as verified by electrochemical impedance measurements. This effect was not so evident for cells prepared by a similar procedure using glass electrodes, revealing that the flexible electrode creates a large series resistance in the solar cell. However, the results obtained for flexible DSSC can be considered very promising for developing solar cells with a lower cost and broader applicability. ${ }^{26}$

\subsection{The dye sensitizer, a coordination compound}

The role of the dye in DSSC consists in acting as a molecular electron pump. It absorbs the visible light, pumps an electron into the semiconductor, accepts an electron from the redox couple in the solution, and then repeats the cycle. ${ }^{6,7}$ To be suitable for application in DSSC, the dyes must present, among other characteristics, a strong absorption in the visible range; high stability and reversibility in the oxidized, ground and excited states; and a suitable redox potential in relation to the semiconductor conduction band edge as well as in relation to the redox charge mediator in the electrolyte, to ensure efficiency in the charge injection and regeneration processes. $^{4,7}$

The molecular design of photosensitizers for application in DSSC accounts for several requirements. , $7,27^{-}$ The most efficient sensitizers in nanocrystalline $\mathrm{TiO}_{2} \mathrm{DSSC}$ are based on bipyridyl complexes of transition metals, particularly ruthenium (II). In general, Ru complexes are suitable as photosensitizers for semiconductors because they show a strong and broad absorption band in the visible range due to metal to ligand charge transfer (MLCT) leading to excited states with long lifetimes. Also, the oxidized $\mathrm{Ru}$ (III) complex has long-term chemical stability, satisfying some of the requirements mentioned above., ${ }^{47}$ Using amphidentate ligands, like $\mathrm{CN}$ - or - $\mathrm{SCN}$, chelation of the metal can take place, leading to some tuning of spectral response. The choice of peripheral groups (axial ligand or chain substituents) can affect the tendency of the dye to aggregate on solution or on the surface. The selection of the anchoring groups of the dye also has a crucial effect in the performance of the DSSC. The anchoring substituent groups at the 4,4'-positions of the bipyridyl rings are employed to ensure the molecular organization of the dye on the oxide surface and to promote electronic coupling of the donor levels of the dye with the acceptor levels of the semiconductor. The preferred anchoring groups for dyes used in solar cells are carboxylic or phosphonic acids, because they react spontaneously with the surface hydroxylic groups of the oxide surfaces to form the corresponding esters, linkages that exhibit good stability. The molecular design of the photosensitizers also accounts for the choice of counterions and the degree of protonation, which are related to the solubility of the dye in organic or aqueous solvents. ${ }^{4}$

The best performance of DSSC, in terms of conversion yield and long-term stability, has been achieved with mesoporous $\mathrm{TiO}_{2}$ films sensitized by the ruthenium complex cis-dithiocyanato bis (2,2'-bipyridyl-4,4'dicarboxylate) $\mathrm{Ru}(\mathrm{II})$, (the red N3 dye), as already discussed in a previous section. ${ }^{5,6,8}$ This dye presents excellent stability, sustaining more than $10^{8}$ turnovers in the DSSC without significant degradation of its performance. In the N3 dye, the carboxylate groups confer a strong binding to the $\mathrm{TiO}_{2}$ surface, while the NCS groups enhance its visible absorption. Its spectrum (Figure 4) is characterized by a strong absorption band centered at $\sim 540 \mathrm{~nm}$, with a long wavelength tail extending to $750 \mathrm{~nm} .{ }^{28}$ The optical transition has MLCT character: excitation of the dye involves transfer of an electron from metal to the $\pi^{*}$ orbital of the surface anchoring carboxylated bipyridyl ligand, from where it is released within femtoseconds into the conduction band of the $\mathrm{TiO}_{2}$, generating electric charge with unit quantum yield. For an N3 dye-sensitized $\mathrm{TiO}_{2}$ solar cell, the photocurrent action spectrum, which measures the incident photon-to-current conversion efficiency to monochromatic radiation (IPCE), exhibited values exceeding $\mathrm{ca} .80 \%$ in the wavelength range between 480 and $600 \mathrm{~nm}$, reaching $85-90 \%$ between 510 and $570 \mathrm{~nm}$. Under illumination at $100 \mathrm{~mW} \mathrm{~cm}^{-2}$ of simulated AM 1.5 solar radiation, the cell presented an overall efficiency of $\eta_{\text {global }}=10 \%$. . $^{8,1028}$

Attempting to further improve the efficiency of such systems requires an enhanced spectral response of the sensitizer toward longer wavelengths, i.e., in the red and

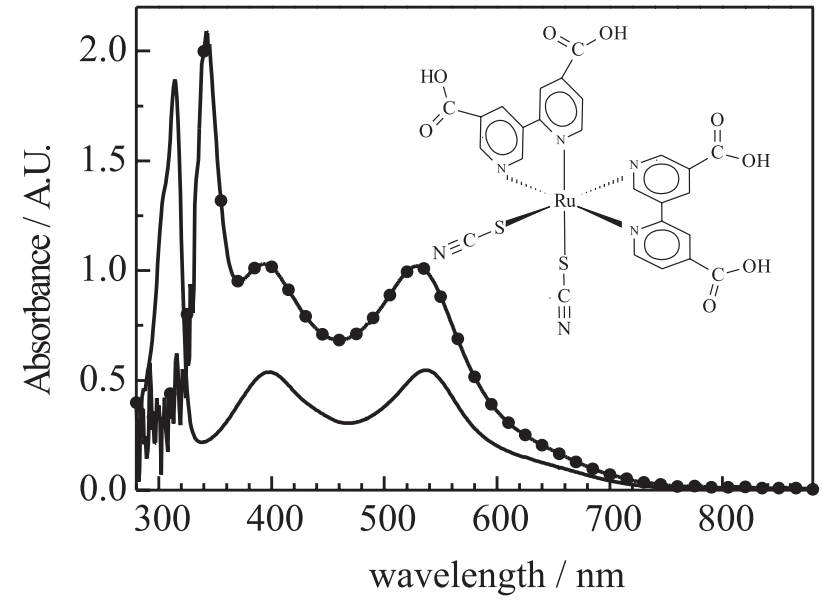

Figure 4. Absorption spectrum of the N3 dye in ethanol solution (-) and of a N3 dye-sensitized nanocrystalline $\mathrm{TiO}_{2}$ electrode (-•-) 
near-IR region. ${ }^{8,29}$ This is accomplished with the dye tris(cyanato)-2,2',2"-terpyridyl-4,4',4"-tricarboxylate) $\mathrm{Ru}(\mathrm{II})$, called "black dye". Black dye displays very efficient panchromatic sensitization of $\mathrm{TiO}_{2}$ over the whole visible range extending to near-IR region up to $920 \mathrm{~nm}$, which results in a better overlap with the solar spectrum. The photocurrent action spectrum for a cell prepared with nanocrystalline $\mathrm{TiO}_{2}$ sensitized with black dye exhibited IPCE values of $c a$. $80 \%$ over a broad wavelength range extending from 400 to $700 \mathrm{~nm}$. Under standard AM 1.5 solar emission, the cell exhibited a photocurrent of $\sim 20$ $\mathrm{mA} \mathrm{cm}{ }^{-2}$ and an overall efficiency exceeding 10\%. ${ }^{8,29}$

Other dyes based on Ru bipyridyl complexes have also been used for sensitization of $\mathrm{TiO}_{2}$, however, the efficiency of the DSSC prepared with these is lower than those prepared with $\mathrm{N} 3$ or black dye. ${ }^{30-32}$ For instance, in an attempting to tune the spectral and redox properties of the N3 dye, one of the carboxylated bipyridyl ligand was modified by replacing the $-\mathrm{COOH}$ groups by the electron donor group $-\mathrm{CH}_{2} \mathrm{~N}\left(\mathrm{CH}_{3}\right)\left(\mathrm{C}_{6} \mathrm{H}_{5}\right)$. However, DSSC prepared using this dye, the cis-dithiocyanato-(4,4'-dicarboxyl-2,2'bipyridyl)-4,4'-di (N,N'-methylphenylaminomethylidene)-2,2'-bipyridyl) Ru(II), called MN3, presented lower performance with lower values of photocurrent, photovoltage and efficiency than those obtained with N3-dye sensitized $\mathrm{TiO}_{2}$ solar cells. The poorer performance was associated with a suppression of the MLCT caused by the presence of the methylphenylamino groups. ${ }^{32}$

Organic dyes have also been used as photosensitizers in DSSC. In spite of the sharp absorption bands of the organic dyes present in the visible region and considerable values for IPCE in the range from 400 to $500 \mathrm{~nm}$, the overall efficiency of the organic DSSC for solar energy-toelectricity conversion was too low, $c a .2 .5 \%$. Recently, with the development of new coumarin dyes with an increased absorption in the visible range, overall efficiencies up to $5 \%$ have been achieved for solar cells prepared with some organic dyes. ${ }^{33}$

\subsection{The electrolyte with the charge mediator, an inorganic salt}

The redox couple in the electrolyte also is of crucial importance for stable operation of a DSSC, because it must carry the charge between the photoelectrode and the counter-electrode for regeneration of the dye. After electron injection, the electron donor in the electrolyte must reduce the oxidized dye to the ground state as rapidly as possible. Thus, the choice of this charge mediator should take into account its redox potential, which must be suitable for regenerating the dye. Also, the redox couple must be fully reversible and should not exhibit significant absorption of visible light. Another important requirement is related to the solvent, which should permit the rapid diffusion of charge carriers, while not causing the desorption of the dye from the oxide surface. ${ }^{4,7}$

The properties of the redox couple in the electrolyte can influence the re-reduction of the oxidized state of the dye as well as several other processes in the DSSC, including electron-transfer kinetics at the counterelectrode, dark current reactions, the process of ion-pairing with the dye and also charge transport in the semiconductor film and in solution. ${ }^{34}$

A very important process for stable operation of the cell and maximum power output is related to the mass transport of charge carriers in the electrolyte by diffusion. This process will depend not only on the viscosity of the solvent but also on the structure of the porous film electrode. The apparent diffusion coefficient of the $\mathrm{I}_{3}{ }^{-}$ion in acetonitrile in $\mathrm{a} \mathrm{TiO}_{2}$ membrane with a porosity of $55 \%$ was measured as $3.4 \times 10^{-6} \mathrm{~cm}^{2} \mathrm{~s}^{-1}$, which is one order of magnitude smaller than free diffusion in the same solvent (at $25^{\circ} \mathrm{C}$ ). Thus, the diffusion of the electroactive species can be obstructed in porous $\mathrm{TiO}_{2}$ film. In a DSSC, this effect can be particularly critical at high light intensities, when large current densities pass through the cell. ${ }^{35}$

The electrolyte also affects the photovoltage of the DSSC, which is related to the Fermi level of the semiconductor and the electrochemical potential of the redox pair. Furthermore, the photovoltage can also be affected by non-electroactive species in the electrolyte, particularly by cations. Cations, for instance $\mathrm{Li}^{+}$, can adsorb onto the surface of the $\mathrm{TiO}_{2}$ electrode, shifting its conduction band edge to a lower energy level. This can lower the photovoltage, but enhance the efficiency of interfacial charge injection, increasing the photocurrent and the efficiency of the DSSC. ${ }^{35,36}$

The most used charge mediator in DSSC is the $\mathrm{I}^{-} / \mathrm{I}_{3}^{-}$ redox couple, since it exhibits an electrochemical redox potential suitable for re-reducion of several oxidized dyes, and the best kinetic properties in DSSC. However, since triiodide solutions are colored and present absorption bands in the visible region, higher concentrations may screen the absorption of the dye. Moreover, since $\mathrm{I}_{3}{ }^{-}$can react with injected electrons (Figure 2, equation 6), higher concentrations can increase the dark current and lower the cell efficiency. Thus, the concentration of $\mathrm{I}^{-} / \mathrm{I}_{3}^{-}$must be optimized. ${ }^{35}$ Also, it is interesting to note that this redox pair is not adequate to regenerate the ground state of some dyes, such as the Os(II) bipyridiyl sensitizers, which need stronger reducing agents. ${ }^{37}$ 
The application of other charge mediators with different electrochemical potentials was also investigated, for instance the pseudo-halogen redox couples $(\mathrm{SeCN})_{2} / \mathrm{SeCN}^{-}$ and $(\mathrm{SCN})_{2} / \mathrm{SCN}^{-}$dissolved in acetonitrile. These pseudohalogens presented a more positive equilibrium potential than the $\mathrm{I}^{-} / \mathrm{I}_{3}^{-}$redox pair, however, the photopotential of the DSSC does not increase as expected, and the cells present a lower efficiency. From transient absorption spectroscopy, it was demonstrated that the lower efficiencies were related to a slower dye regeneration rate when $\mathrm{SCN}^{-}$or $\mathrm{SeCN}^{-}$were used in place of $\mathrm{I}^{-} .^{34}$

Also, when discussing the electrolyte in DSSC, it is worthwhile to consider the sealing necessary to prevent the loss of the electrolyte by leakage and/or evaporation of the solvent. Thus, liquid junction dye-sensitized solar cells also need perfect sealing, with a material resistant to the electrolyte, which is usually an organic solvent containing the corrosive $\mathrm{I}^{-/} \mathrm{I}_{3}^{-}$redox couple. Since the problems related to the use of the liquid electrolyte are the main factors that slowed the commercial development of the DSSC, several attempts have been made to find a suitable substitute.

One of the approaches consists in replacing the liquid electrolyte by hole conductor materials, such as CuI, CuSCN and 2,2',7,7'-tetrakis (N,N-di-p-methoxyphenylamine)-9,9'-spirobifluorene (Spiro-MeOTAD). ${ }^{38}$ However, the cells generally are very unstable and exhibit efficiencies lower than $1 \%$. Recently, a better performance was reported for a solid-state DSSC prepared with crystallites of CuI (average diameter ca. $100 \mathrm{~nm}$ ), which were deposited from acetonitrile with a crystal growth inhibitor, 1-methyl-3-ethylimidazoliumthiocyanate (MEISCN). These cells exhibited $\mathrm{I}_{\mathrm{SC}}=9.5 \mathrm{~mA} \mathrm{~cm}^{-2}$ and an initial overall efficiency of $3 \%$, which decayed to $2.2 \%$ after 10 days (the area of the cell was not specified). Using a similar procedure but without MEISCN, larger $\mathrm{CuI}$ crystals $(\sim 10 \mathrm{~mm})$ were deposited and the resulting DSSC presented the same initial efficiency, decaying to $0.3 \%$ in the same period of time. The enhanced performance was associated with the successful strategy used for depositing small crystallites of $\mathrm{CuI}$ which filled the $\mathrm{TiO}_{2}$ pores, enabling good contact of the sensitized oxide with the hole collector. ${ }^{39}$

In general, more interesting results have been obtained for solid-state $\mathrm{TiO}_{2}$ DSSC assembled with the $\mathrm{I}^{-} / \mathrm{I}_{3}^{-}$redox pair in molten salts. For instance, DSSC assembled with low temperature molten salts based on methyl-imidazolium compounds, such as methyl-hexyl-imidazolium iodide, exhibited $\mathrm{I}_{\mathrm{SC}}$ values ranging from 1 to $6 \mathrm{~mA} \mathrm{~cm}^{-2}$, and efficiencies of 0.4 to $2 \%$, depending on the viscosity of the medium. The studies revealed a slow diffusion of $\mathrm{I}^{-} / \mathrm{I}_{3}$ redox species due to the high viscosity of these molten salts; decreasing the viscosity of the medium caused an improvement in the performance of the solar cell. ${ }^{40}$

Improved performance has been exhibited by $\mathrm{TiO}_{2}$ DSSC prepared with the $\mathrm{I}^{-} / \mathrm{I}_{3}{ }^{-}$redox couple dissolved in solid or gel polymer electrolytes based on poly (ethylene oxide), ${ }^{41-46}$ poly (acrylonitrile), ${ }^{47}$ or using different kind of gelators. ${ }^{48}$ Up to this time, the best reported results were obtained when a composite of poly (ethylene oxide)/ $/ \mathrm{TiO}_{2}$ and $\mathrm{I}^{-} / \mathrm{I}_{3}^{-}$was used as polymer electrolyte for a N3 dyesensitized $\mathrm{TiO}_{2}$ solar cell (with an active area $0.25 \mathrm{~cm}^{2}$ ), which presented $\mathrm{h}_{\text {global }}=4.2 \%$ under $65 \mathrm{~mW} \mathrm{~cm}^{-2}{ }^{41}$ Promising results have also been obtained by De Paoli coworkers $^{43}$ using a polymer electrolyte based on the copolymer poly (ethylene oxide-co-epichlorohydrin), $\mathrm{P}(\mathrm{EO}-\mathrm{EPI})_{84: 16}$, produced by Daiso Co. Ltd., Osaka. The best energy conversion efficiency obtained for this solidstate $\mathrm{N} 3 \mathrm{TiO}_{2} /$ dye cell (with an active area of $1 \mathrm{~cm}^{2}$ ) was $\eta_{\text {global }}=2.6 \%$ under $10 \mathrm{~mW} \mathrm{~cm}^{-2}\left(\eta_{\text {global }}=1.6 \%\right.$ under 100 $\mathrm{mW} \mathrm{cm}{ }^{-2}$ ). However, comparison with results reported in the literature is not straightforward, since the area of the reported cells (not always reported) can be very different. The efficiency of DSSC decreases considerably when enlarging the cell area, due to the increase in the series resistance, and this effect can be even more important when using polymer electrolytes.

As a general rule, all the DSSC assembled with the redox couple $\mathrm{I}^{-} / \mathrm{I}_{3}$ - in polymer electrolytes exhibited lower efficiency than the cells assembled using liquid electrolytes. This effect is caused by the lower ionic mobility of the $\mathrm{I}^{-} / \mathrm{I}_{3}^{-}$species in the polymeric medium, which affects the kinetics of all the processes involved for the cell operation. But, in spite of the lower performance, the benefits obtained by the replacement of the liquid electrolyte can be worthwhile in achieving cells with better efficiency and stability.

\subsection{The counter-electrode, a platinum catalyst}

After considering the characteristics of the porous semiconductor oxide, the sensitizer dye and the electrolyte containing the charge mediator, which allows dye regeneration, another essential material for an operative DSSC is the counter-electrode, where the regeneration of the charge mediator takes place. The first requirement for a material to be used as counter-electrode in a DSSC is a low charge-transfer resistance and high exchange current densities for the reduction of the oxidized form of the charge mediator (Figure 2, equation 5). Also, such materials must present chemical and electrochemical stability in the electrolyte medium used in the cell. ${ }^{4,49}$ 
As already discussed, the best charge mediator for most of the DSSC is the $\mathrm{I}^{-/} \mathrm{I}_{3}^{-}$redox couple. Unfortunately however, the iodine (and triiodide) reduction reaction is not reversible in several materials and its kinetics is solvent dependent. For instance, at the surface of transparent glassITO or glass-FTO electrodes, the electron-transfer kinetics for reduction of triiodide to iodide (Figure 2, equation 5) is very slow. The best material that acts as a catalyst and provides high exchange current for this reaction is platinum, particularly as thin films deposited by thermal oxidation of hexachloroplatinate. Pt thin films obtained by sputtering also exhibited good performance as counterelectrodes in DSSC, but are more expensive. ${ }^{49}$

The usual procedure to prepare the counter-electrode for DSSC consists in spreading a small quantity of a $c a .5$ mmol L-1 hexachloroplatinic acid solution in isopropanol on the conductive surface of a glass-FTO electrode and heating the coated electrode at $385^{\circ} \mathrm{C}$ for 10 minutes. The electrodes prepared by such a procedure remain almost transparent, which can be very useful, since the cell can be irradiated from both sides. Moreover, they present low charge-transfer resistance and high kinetic performance for the $\mathrm{I}_{3}^{-}$reduction reaction. This ensures high exchange current densities at the $\mathrm{CE}$, and thus the processes at the $\mathrm{CE}$ do not become rate limiting for the processes for solar energy conversion. ${ }^{49}$

\section{Combining All Materials in Solar Cells Assembled with Polymer Electrolytes: Overview and Perspectives}

Before presenting an overview of the results obtained with a solid-state version of the $\mathrm{TiO}_{2} /$ dye cell using a polymer electrolyte, it is worthwhile introducing some considerations about this kind of electrolyte. In polymer electrolytes, the polymer matrix should be an efficient solvent for the salt, capable of dissociating it and minimizing the formation of ion pairs. The solubility of the salt relies on the ability of the electron donor atoms in the polymer chain to coordinate with the cation of the salt through a Lewis acid-base interaction. This interaction also depends on the lattice energy of the salt and the structure of the host polymer. The mechanism for ionic motion in polymer electrolytes results from a solvationdesolvation process along the chains, which occurs predominantly in the amorphous polymer phase. Since the ionic motion is strictly correlated with the segmental motion of the polymer chains, the ionic conductivity increases with increasing chain flexibility. The ionic conductivity is also a function of the number of charge carriers in the polymer matrix. However, a high salt concentration can reduce the segmental motion of the polymer chains and decrease the ionic conductivity. ${ }^{50}$

Particularly for poly (ethylene oxide), PEO, the repeating unit $\left(-\mathrm{CH}_{2}-\mathrm{CH}_{2}-\mathrm{O}-\right)$ seems to present a favorable arrangement for effective interaction of the free electron pair on the oxygen with alkali metal cations. This occurs because PEO chains are capable of adopting a helical conformation with an oxygen-lined cavity that presents ideal distances for oxygen-ion interactions. Due to this interaction, the ionic conductivity is associated with the concentration ratio of oxygen in the ethylene oxide repeating units and the cations of the salt, $\eta_{\mathrm{EO}}=[\mathrm{O}]_{\mathrm{EO}} /$ [cation]. PEO is characterized by a low glass transition temperature $\left(\mathrm{T}_{\mathrm{g}}=-50^{\circ} \mathrm{C}\right)$, but the regular structure favors a high degree of crystallinity $(\sim 80 \%)$, with its melting point at $\mathrm{T}_{\mathrm{f}}=65^{\circ} \mathrm{C}$. To obtain amorphous materials at ambient temperature, it is necessary to introduce some "disorder" in the structure. This is achieved by crosslinks in the network using co-polymers of PEO, such as acrylic polymers, and also by incorporating silica or other oxides. ${ }^{50,51}$ Such approaches have already been attempted in polymer electrolytes for application in DSSC. ${ }^{41-47}$

The polymer electrolyte used in studies by the authors with DSSC consisted of a complex of $\mathrm{NaI}$ and $\mathrm{I}_{2}$ with the copolymer poly (epichlorohydrin-co-ethylene oxide), $\mathrm{P}(\mathrm{EO}-\mathrm{EPI})_{84: 16}$, supplied by Daiso Co. Ltd., Osaka, which presented a molar mass of $1.3 \times 10^{6} \mathrm{~g} \mathrm{~mol}^{-1}$. Initially, the characterization of polymer electrolytes consisting of $\mathrm{P}(\mathrm{EO}-\mathrm{EPI})_{84: 16}$ with different concentrations of $\mathrm{NaI}$ and $\mathrm{I}_{2}$ was performed by measurements of ionic conductivity, differential scanning calorimetry and thermogravimetry.52 Figure 5 shows the variation of the conductivity of the

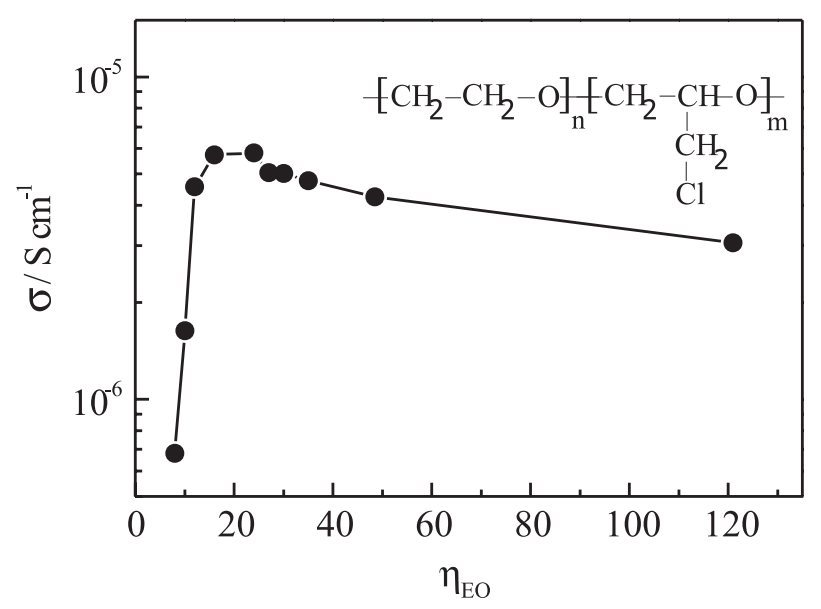

Figure 5. Variation of the ionic conductivity of the polymer electrolyte $\mathrm{P}(\mathrm{EO}-\mathrm{EPI})_{84: 16}$ with the concentration of NaI, expressed as a function of the ratio $h_{\mathrm{EO}}=[\mathrm{O}]_{\mathrm{EO}} /[\mathrm{Na}]$. Measurements performed in a dry box at $26^{\circ} \mathrm{C}$. The structure of the copolymer poly (ethylene oxide-co-epichlorohydrin), where $\mathrm{n}$ and $\mathrm{m}$ are 0.84 and 0.16 , respectively, for $\mathrm{P}(\mathrm{EO}-\mathrm{EPI})_{84: 16}$, are also shown. 
polymer electrolyte with the concentration of $\mathrm{NaI}$, expressed as a function of the ratio $\eta_{\mathrm{EO}}=[\mathrm{O}]_{\mathrm{EO}} /[\mathrm{Na}]$, determined in a dry box at $26{ }^{\circ} \mathrm{C}$. Initially, with the increasing number of charge carriers, the ionic conductivity increases with the NaI concentration. However, after reaching a maximum value, it decreases because higher salt concentrations lower the segmental motion of the polymeric chains, as mentioned before. For this system, the highest conductivity, $5.6 \times 10^{-6} \mathrm{~S} \mathrm{~cm}^{-1}$, was seen at $\eta_{\mathrm{EO}}=24$, which corresponds to a $9 \%(\mathrm{~m} / \mathrm{m}) \mathrm{NaI}$ concentration. $^{52}$

Considering these results, in most of the studies, the DSSC were assembled using a polymer electrolyte consisting of $\mathrm{P}(\mathrm{EO}-\mathrm{EPI})_{84: 16}$ containing $9 \% \mathrm{NaI}$ and $0.9 \%$ $\mathrm{I}_{2}(\mathrm{~m} / \mathrm{m})$. Usually, the cells were prepared by spreading a small aliquot of $\mathrm{TiO}_{2}$ suspension on the surface of glassFTO electrodes using a glass rod, with adhesive tape as spacer $(\sim 40-50 \mu \mathrm{m})$, followed by heating at $450{ }^{\circ} \mathrm{C}$ for 30 $\mathrm{min}$. The glass-FTO|TiO electrodes were immersed overnight ( $c a .16 \mathrm{~h}$ ) in a $\sim 1.5 \times 10^{-4} \mathrm{~mol} \mathrm{~L}^{-1}$ solution of N3 dye sensitizer, rinsed with ethanol and dried. Afterwards, a film of the polymer electrolyte was deposited onto the sensitized electrodes by casting, using a solution of $\mathrm{P}(\mathrm{EO}-\mathrm{EPI})_{84: 16}$ with $\mathrm{NaI}$ and $\mathrm{I}_{2}$ in acetone. The assembly of the cells was completed by pressing the Pt counter electrode against the sensitized electrodes coated with the polymer electrolyte. The active area of the cells was typically $1 \mathrm{~cm}^{2}$. Variations in this procedure used different $\mathrm{TiO}_{2}$ suspensions, slight variations in the composition of the polymer electrolyte, including eventual addition of a small quantity of LiI, as well as the use of different counterelectrodes. The counter-electrodes consisted of a thin Pt film deposited onto glass-FTO electrodes by sputtering or by thermal deposition from a solution of hexachloroplatinic acid in isopropanol $\left(385{ }^{\circ} \mathrm{C}\right)$. Flexible cells were also investigated, using flexible PET-ITO electrodes as substrate for both photoelectrode and counter-electrode, but different procedures were used for preparing the $\mathrm{TiO}_{2}$ film. ${ }^{24-26}$ The best results were obtained when, after spreading a film of $\mathrm{TiO}_{2}$ particles from an aqueous solution, the PET-ITO $\mid \mathrm{TiO}_{2}$ was exposed to UV irradiation for $15 \mathrm{~min}$ and then heated at $140{ }^{\circ} \mathrm{C}$ for $2 \mathrm{~h}$ in an oven in a dry box. ${ }^{26}$ The sensitization and assembling of the cell was performed as previously described. Thus, use of a polymer electrolyte makes the assembly of the DSSC much easier.

The investigation of the energy conversion performance of these cells was performed using different techniques, including determination of current-potential curves, photocurrent action spectra (IPCE), and measurements by electrochemical impedance spectroscopy (EIS) under visible light irradiation. Measurements of transient absorption spectroscopy wee also performed to investigate the electron-transfer dynamics in the cells.

The performance exhibited by an $\mathrm{N} 3$ dye-sensitized $\mathrm{TiO}_{2}$ solar cell with $\mathrm{P}(\mathrm{EO}-\mathrm{EPI}) / \mathrm{I}^{-} / \mathrm{I}_{3}^{-}$polymer electrolyte can be evaluated from Figure 6, which shows some typical I-V curves obtained under different light intensities, as well as, in the insert, the photocurrent action spectrum, obtained by irradiating the cell from the $\mathrm{FTO}-\mathrm{TiO}_{2}$ side (SE) and from the counter-electrode side (EE). The IPCE curves shows that the maximum photocurrent values were obtained at $c a .520$ $\mathrm{nm}$, corresponding to 51 and $40 \%$ for SE and EE irradiation, respectively. From the I-V curves, at irradiation of $100 \mathrm{~mW}$ $\mathrm{cm}^{-2}$, the cell presented $\mathrm{I}_{\mathrm{SC}}=4.2 \mathrm{~mA} \mathrm{~cm}^{-2}, \mathrm{~V}_{\mathrm{OC}}=0.82 \mathrm{~V}$ and efficiency $\eta_{\text {global }}=1.6 \%$. The $\mathrm{V}_{\mathrm{OC}}$ values are high and could result from interactions of the basic copolymer with the acid sites of the $\mathrm{TiO}_{2}$ surface, which could suppress part of the dark current, as already discussed. However, the values of photocurrent and overall efficiency are lower than those exhibited by DSSC assembled with liquid electrolytes, and both decreased with increasing light intensity. This characteristic of the DSSC with polymer electrolytes is related to the lower ionic mobility of $\mathrm{I}^{-} \mathrm{I}_{3}^{-}$species in this medium, which retards the kinetics of the dye regeneration reaction (Figure 2, equation 4) ${ }^{43}$.

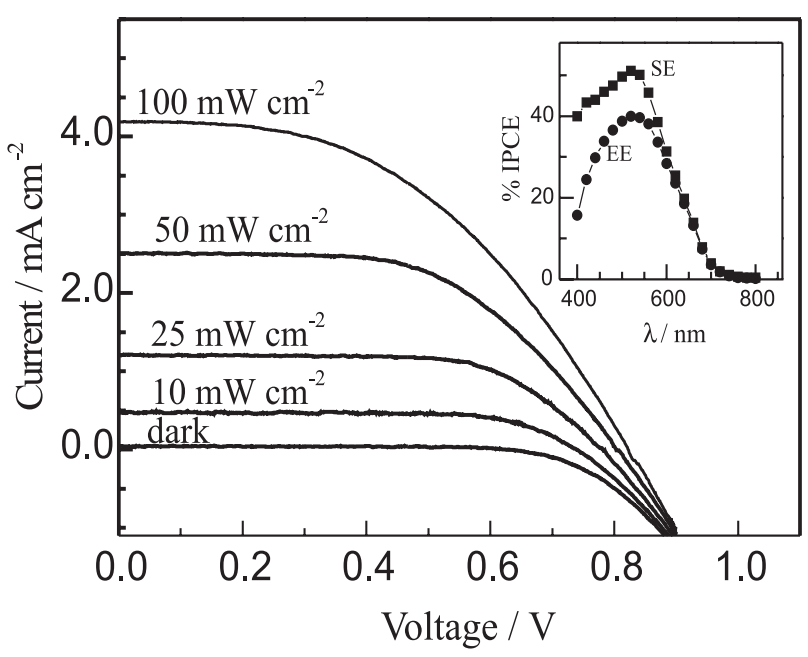

Figure 6. Typical I-V curves obtained at different light intensities for an $\mathrm{N} 3$ dye-sensitized $\mathrm{TiO}_{2}$ solar cell assembled with $\mathrm{P}(\mathrm{EO}-\mathrm{EPI}) /$ $\mathrm{I}^{-} / \mathrm{I}_{3}^{-}$polymer electrolyte. In the insert, photocurrent action spectrum determined by irradiating the cell from the FTO-TiO 2 side (SE) or counter-electrode side (EE).

Transient absorption spectroscopy measurements confirmed this assumption. The kinetics of dye cation reduction by iodide ions in the polymer electrolyte medium exhibited a half life of $50 \mathrm{~ms}$, which is 2-3 orders of magnitude slower than that observed in acetonitrile. As previously discussed, the kinetics for this reaction can also affect other processes that occur during cell operation, increasing, for 
instance, the probability for recombination reactions of injected electrons with the dye cation and with triiodide, which lower the cell efficiency. This effect must become even more critical for high light intensities, when the demand of charge carrier transport between the electrodes is higher. ${ }^{43}$

This light intensity dependent performance of the cell can be observed from the I-V curves. To fit the I-V curves exhibited by these solar cells it is necessary to use a twodiode model, with a term that express a light dependent recombination current. Using this model, good fits were obtained for all the curves represented in Figure 7. Among other parameters obtained from the fitting, the series resistance was estimated as $R_{S}=60 \Omega$. This high $R_{S}$ is consistent with the low ionic conductivity of the polymer electrolyte. ${ }^{43}$

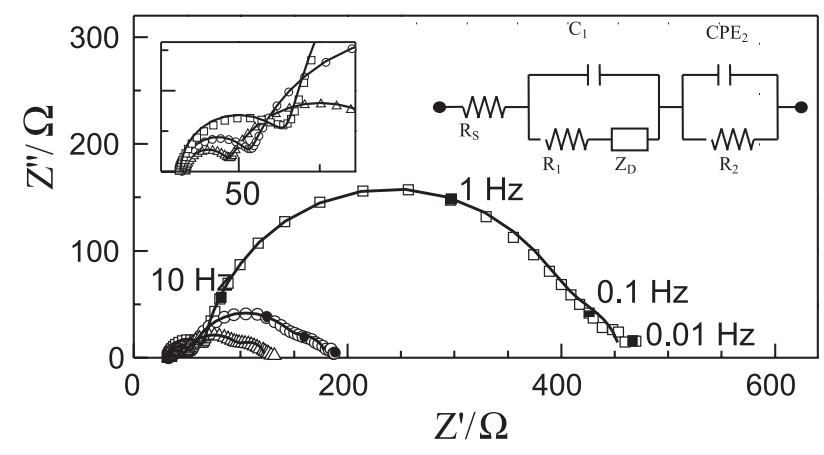

Figure 7. Nyquist representation of the impedance data obtained for a solid-state $\mathrm{N} 3$ dye-sensitized $\mathrm{TiO}_{2}$ solar cell prepared with $\mathrm{P}(\mathrm{EO}-\mathrm{EPI}) / \mathrm{I}^{-} / \mathrm{I}_{3}^{-}$polymer electrolyte. Experimental data are represented by symbols and solid lines correspond to fits obtained with Boukamp software using the circuit presented in the Figure. The insert presents the magnification of the high frequency region.

Investigation by electrochemical impedance spectroscopy also gives an estimation of the series resistance and reveals that this parameter also depends on the characteristics of the $\mathrm{TiO}_{2}$ photoelectrode, including the method used for preparing the $\mathrm{TiO}_{2}$ film and the substrate. ${ }^{25,26}$ For instance, the $\mathrm{R}_{\mathrm{S}}$ values for different solid-state DSSC assembled with glass-FTO $\mid \mathrm{TiO}_{2}$ photoelectrodes were determined as 35-50 $\Omega$, which is the same magnitude as the value estimated from fitting the I-V curves. On the other hand, the flexible cells assembled with PET-ITO electrodes exhibited $R_{S} \sim 400 \Omega$, which can be related to poor electrical contact between the particles in the $\mathrm{TiO}_{2}$ network, due to the low sintering temperature. Also, all the impedance spectra determined for the DSSC assembled with polymer electrolyte exhibited a low frequency response, which can be associated with diffusion processes in the electrolyte.

Figure 7 shows some typical Nyquist diagrams of the impedance spectra obtained using a small perturbation $\left( \pm 10 \mathrm{mV}\right.$ ) over the $\mathrm{V}_{\mathrm{OC}}$ of the cell and under different light intensities for a $\mathrm{N} 3$ dye-sensitized $\mathrm{TiO}_{2}$ solar cell assembled with $\mathrm{P}(\mathrm{EO}-\mathrm{EPI}) / \mathrm{I}^{-/} \mathrm{I}_{3}^{-}$and using glass-FTO electrodes. Experimental data are represented by symbols while the solid lines correspond to the fit obtained with Boukamp software using the equivalent circuit $\mathrm{R}_{\mathrm{S}}\left[\mathrm{C}_{1}\left(\mathrm{R}_{1} \mathrm{Z}_{\text {Dif1 } 1}\right)\right]$ $\left(\mathrm{R}_{2} \mathrm{CPE}_{2}\right)$, depicted in the insert. In this circuit, the symbols $\mathrm{R}$ and $\mathrm{C}$ describe resistance and capacitance, respectively; $\mathrm{Z}_{\text {Dif }}$ accounts for a finite-length Warburg diffusion, and CPE is the symbol for the constant phase element. The CPE is a non ideal frequency dependent capacitance, a characteristic that can be associated with a distribution of relaxation times or with a non uniform distribution of current due to material heterogeneity. ${ }^{25}$ The insert also shows the magnification of the high-frequency region. In general, the impedance spectra of these solid-state solar cells also present dependence on light intensity. In the dark (curve not shown), the solar cell presented high impedance and the time constants were not well defined. Under illumination, three semicircles could be identified in the Nyquist diagrams of the EIS spectra. At high frequencies, the response associated with a small capacitance $\left(\sim 12 \mu \mathrm{F} \mathrm{cm}^{-2}\right)$, which was almost independent of illumination, was attributed to the interface at the $\mathrm{Pt}$ electrolyte interface $\left(\mathrm{C}_{1}\right.$ and $\mathrm{R}_{1}$ elements $)$. The response at medium frequencies, related to a high capacitance that strongly depended on light intensity, was attributed to the $\mathrm{TiO}_{2}$ | electrolyte ( $\mathrm{R}_{2} \mathrm{CPE}$ elements), since an accumulation of electrons and redox species is expected at this interface under open circuit conditions. The response at low frequencies was associated with diffusion processes in the electrolyte, considering the lower mobility of the $\mathrm{I}_{3}^{-}$species in the polymer electrolyte.

The general behavior of all the spectra determined by the authors for different cells was quite similar, but the impedance of the flexible cells was higher than that exhibited by cells prepared using glass electrodes. ${ }^{25}$ It is interesting to compare the results obtained from I-V curves and the EIS measurements for cells prepared using glass and flexible electrodes. Both kinds of cell exhibited similar values of $\mathrm{V}_{\mathrm{OC}}$, but the flexible cell presented values of photocurrent $c a$. 10 times smaller and $\mathrm{R}_{\mathrm{S}} 10$ times larger than the cells assembled with glass electrodes. The stability of these flexible cells was investigated over 50 days. Concomitant to the decrease in photocurrent and efficiency values observed from I-V curves, EIS measurements revealed an increase of $R_{S}$ with time. Thus, it can be inferred that the high $R_{S}$, which increases with time, is responsible for the lower performance and stability exhibited by the flexible cells. However, these results are still very promising for developing solid-state, flexible solar cells with lower costs and broader applicability. 
In general, these solid-state $\mathrm{TiO}_{2}$ /dye solar cells, prepared with glass or flexible electrodes, present low current but high photovoltage values, even under low illumination conditions. With this performance, they can be considered suitable for indoor applications. ${ }^{4}$

Present studies by the authors include the characterization of a new polymer electrolyte, consisting of $78 \%$ ethylene oxide and $22 \%$ diethylene glycol glycidyl methyl ether, poly(EO-DGME) ${ }_{78: 22}$ (also provided by Daiso Co. Ltd., Osaka). Preliminary studies revealed that this copolymer can also be used in polymer electrolytes with $\mathrm{I}^{-} / \mathrm{I}_{3}^{-}$, for application in DSSC. It allows the dissolution of a higher concentration of NaI, which can enhance the performance of the solar cell. Also, alternative methods for depositing $\mathrm{TiO}_{2}$ films with larger pores are under investigation for assembling cells with polymer electrolytes.

\section{Conclusion}

Dye-sensitized $\mathrm{TiO}_{2}$ solar cells are a successful combination of materials, usually consisting of a dyesensitized nanocrystalline $\mathrm{TiO}_{2}$ film, an electrolyte with an $\mathrm{I} / \mathrm{I}_{3}-$ redox couple and a Pt counter-electrode. In addition to practical interests, as an alternative energy source, these devices are also very fascinating systems from a scientific point of view, in which light can be converted to electrical energy through complex energy and charge transfer processes.

The overall efficiency in energy conversion depends critically on the individual properties of the constituents of the cell. Enhancement of its performance involves understanding and controlling the properties of each component, and knowing how they affect the related processes in energy conversion.

\section{Acknowledgments}

Authors acknowledge financial support from FAPESP (fellowship 00/03086-3), PRONEx/CNPq, and thank Daiso Co. Ltd. Osaka, Japan, for providing the polymer electrolyte. We thank Prof. Durrant (Imperial College, London) and Prof. De Cola (University of Amsterdam, Amsterdam) for collaboration in the transient spectroscopy measurements.

\section{References}

1. Licht, S.; Sol. Energy Mater. Sol. Cells 1995, 38, 305; Smestad, G.P.; Sol. Energy Mater. Sol. Cells 1998, 55, 157.

2. Grätzel, M.; Nature 2001, 414, 338.

3. Yan, S.G; Lyon, L.A.; Lemon, B.I.; Preiskorn, J.S.; Hupp, J.T.; J. Chem. Educ. 1997, 74, 657.
4. Kalyanasundaram, K; Grätzel, M.; Coord. Chem. Rev. 1998, 177, 347.

5. O’Reagan, B.; Grätzel, M.; Nature 1991, 353, 737.

6. Hagfeldt, A.; Grätzel, M.; Chem. Rev. 1995, 95, 49.

7. Kelly, C.A; Meyer, G.J.; Coord. Chem. Rev. 2001, 211, 295; Meyer, G.J., J. Chem. Educ. 1997, 74, 652.

8. Grätzel, M.; Curr. Opin. Colloid Interface Sci. 1999, 314.

9. The United States Patent and Trademark Office, www.uspto.gov, August 11, 2003.

10. Nazeeruddin, M.K.; Kay, A.; Rodicio, I.; Humphry-Baker, R.; Müller, E.; Liska, P.; Vlachopoulos, N.; Grätzel, M.; J. Am. Chem. Soc. 1993, 115, 6382.

11. Pelet, S.; Moser, J.E.; Grätzel, M.; J. Phys. Chem. B 2000, 104, 1791; Haque, S.A.; Tachibana, Y.; Willis, R.L.; Moser, J.E.; Grätzel, M.; Klug, D.R.; Durrant, J.R.; J. Phys. Chem. B 2000, 104, 538.

12. Fisher, A.C.; Peter, L.M.; Ponomarev, E.A.; Walker, A.B.; Wijayantha, K.G.U.; J. Phys. Chem. B 2000, 104, 949.

13. Mora-Seró, I.; Bisquert, J.; Nano Lett. 2003, 3, 945; Bisquert, J.; Zaban, A.; Salvador, P.; J. Phys. Chem. B 2002, 106, 8774; Jakob, M.; Levanon, H.; Kamat, P.V.; Nano Lett. 2003, 3, 353; de Jongh, P.E.; Vanmaekelbergh, D.; Phys. Rev. Lett. 1996, 77, 3427.

14. Papageorgiou, N.; Barbe, C.; Grätzel, M.; J. Phys. Chem. B 1998, 102, 4156.

15. Barbé, C.J.; Arendse, F.; Comte, P.; Jirousek, M.; Lenzmann, F.; Shkhlover, V.; Grätzel, M.; J. Am. Ceram. Soc. 1997, 80, 3157; Benkö, G.; Skårman, B.; Wallenberg, R.; Hagfeldt, A.; Sundström, V.; Yartsev, A.P.; J. Phys. Chem. B 2003, 107, 1370.

16. Ito, S.; Kitamura, T.; Wada, Y.; Yanagida, S.; Sol. Energy Mater. Sol. Cells 2003, 76, 3

17. Gomez, M.M.; Lu, J; Olsson, E.; Hagfeldt, A.; Granqvist, C.G.; Sol. Energy Mater. Sol. Cells 2000, 64, 385; Gomez, M.M.; Beermann, N.; Lu, J; Olsson, E.; Hagfeldt, A.; Niklasson, G.A.; Granqvist, C.G.; Sol. Energy Mater. Sol. Cells 2003, 76, 37.

18. Jung, K.-H.; Hong, J.S.; Vittal, R.; Kim, K.; Chem. Lett. 2002 864.

19. Diamant, Y.; Chen, S.G.; Melamed, O.; Zaban, A.; J. Phys. Chem. B 2003, 107, 1977.

20. Longo, C.; Sanz, F.; Abadal, G.; Sumodjo, P.T.A.; J. Electrochem. Soc. 1999, 146, 977; Cachet, H.; Zenia, F.; Froment, M.; J. Electrochem. Soc. 1999, 146, 2169.

21. Pichot, F.; Ferrere, S.; Pitts, R.J.; Gregg, B.A.; J. Electrochem. Soc. 1999, 146, 4324.

22. Sommeling, P.M.; Späth, M.; Kroon, J.; Kinderman, R.; van Roosmalen, J.; Proc. 16th European Photovoltaic Solar Energy Conference and Exhibition, Glasgow, 2000.

23. Lindström, H.; Holmberg, A.; Magnusson, E.; Malmqvist, L.; Hagfeldt, A.; J. Photochem. Photobiol. A: Chem. 2001, 145, 107; Boschloo, G.; Lindström, H.; Magnusson, E.; Holmberg, A.; Hagfeldt, A.; J. Photochem. Photobiol. A: Chem. 2002, $148,11$. 
24. De Paoli, M.-A.; Machado, D.A; Nogueira, A.F.; Longo, C.; Electrochim. Acta 2001, 46, 4243.

25. Longo, C.; Nogueira, A.F.; De Paoli, M.-A.; Cachet, H.; J. Phys. Chem.B 2002, 106, 5925.

26. Longo, C.; Freitas, J.N.; De Paoli, M.-A.; J. Photochem. Photobiol. A: Chem. 2003, 159, 33.

27. Garcia, C.G.; Lima, J.F.; Murakami Iha, N.Y.; Coord. Chem. Rev. 2000, 196, 219; Murakami Iha, N.Y.; An. Acad. Bras. Cienc. 2000, 72, 67.

28. Tachibana, Y.; Moser, J.E.; Grätzel, M.; Klug, D.R.; Durrant, J.R.; J. Phys. Chem. 1996, 100, 20056.

29. Nazeeruddin, Md. K.; Péchy, P.; Grätzel, M.; J. Chem. Soc. Chem. Commun. 1997, 1705; Nazeeruddin, Md. K.; Péchy, P.; Renouard, T.; Humphry-Baker, R.; Comte, P.; Liska, P.; Cevey, L.; Costa, E.; Shklover, V.; Spiccia, L.; Deacon, G.B.; Bignozzi, C.A.; Grätzel, M.; J. Am. Chem. Soc. 2001, 123,1613; Bauer, C.; Boschloo, G.; Mukhtar, E.; Hagfeldt, A.; J. Phys. Chem. 2002, 106, 12693; Zakeeruyddin, S.M.; Nazeeruddin, Md. K.; Humphry-Baker, R.; Péchy, P.; Quagliotto, P.; Barolo, C.; Viscardi, G.; Grätzel, M.; Langmuir 2002, 18, 952.

30. Garcia, C.G.; Kleverlaan, C.J.; Bignozzi, C.A.; Murakami Iha, N.Y.; J. Photochem. Photobiol. A: Chem. 2002, 147, 143; Garcia, C.G.; Nakano, A.K.; Kleverlaan, C.J.; Murakami Iha, N.Y.; J. Photochem. Photobiol. A: Chem. 2002, 151, 165.

31. Bernard, M.C.; Cachet, H.; Falaras, P.; Hugot le Goff, A.; Kalbac, M.; Lukes, I.; Oanh, N.T.; Stergiopolous, T.; Arabatzis, I.; J. Electrochem. Soc. 2003, 150, E155.

32. Yao, Q.-H.; Huang, Y.-Y.; Song, L.-Q.; Zhang, B.W.; Huang, C.-H.; Wang, Z.-S.; Li, F.-Y.; Zhao, X.-S.; Sol. Energy Mater. Sol. Cells 2003, 77, 319.

33. Hara, K.; Sato T.; Katoh, R.; Furube, A.; Ohga, Y.; Shinpo A.; Suga, S.; Sayama, K.; Sugihara, H.; Arakawa, H.; J. Phys. Chem. B 2003, 107, 597; Hara, K.;Tachibana, Y.; Ohga, Y.; Shinpo A.; Suga, S.; Sayama, K.; Sugihara, H.; Arakawa, H.; Sol. Energy Mater. Sol. Cells 2003, 77, 89.

34. Oskam, G.; Bergeron, B.V.; Meyer, G.J.; Searson, P.C.; J. Phys. Chem. B 2001, 105, 6867.

35. Kebede, Z.; Lindquist, S.-E.; Sol. Energy Mater. Sol. Cells 1998, 51, 291; Liu, Y.; Hagfeldt, A.; Xiao, X.-R.; Lindquist, S.-E.; Sol. Energy Mater. Sol. Cells 1998, 55, 267.

36. Kelly, C.A.; Fazard, F.; Thompson, D.W.; Stipkala, J.M.; Meyer, G.J.; Langmuir 1999, 15, 7047.

37. Kuciauskas, D.; Freund, M.S.; Gray, H.B.; Winkler, J.R.; Lewis, N.S.; J. Phys. Chem. B 2001, 105, 392; Alebbi, M.; Bignozzi, C.A.; Heimer, T.A.; Hasselmann, G.M.; Meyer, G.J.; J. Phys. Chem. B 1998, 102, 7577.

38. Kruger, J.; Plass, R.; Grätzel, M.; Matthieu, H.J.; App. Phys. Lett. 2002, 81, 367; Bach, U.; Lupo, D.; Comte, P.; Moser, J.E.; Weissörtel, F.; Salbeck, J.; Spreitzer, H.; Grätzel, M.; Nature
1998, 395, 583; Murakoshi, K.; Kogure, R.; Wada, Y.; Yanagida, S.; Sol. Energy Mater. Sol. Cells 1998, 55, 113; Tennakone, K.; Senadeera, G.K.R.; De Silva, D.B.R.A.; Kottegoda, I.R.M.; Appl. Phys. Lett. 2000, 77, 2367; Gebeyehu, D.; Brabec, C.J.; Padinger, F.; Fromherz, T.; Spiekermann, S.; Vachopoulos, N.; Kienberger, F.; Schindler, H.; Sariciftci, N.S.; Synth. Met. 2001, 121, 1549.

39. Kumara, G.R.A.; Konno, A.; Shiratsuchi, K.; Tsukahara, J.; Tennakone, K.; Chem. Mater. 2002, 14, 954.

40. Matsumoto, H.; Matsuda, T.; Tsuda, T.; Hagiwara, R.; Ito, Y.; Miyazaki, Y.; Chem. Lett. 2001, 26; Papageorgiou, N.; Athanassov, Y.; Armand, M.; Bonhôte, P.; Petterson, H.; Azam, A.; Grätzel, M.; J. Electrochem. Soc. 1996, 143, 3099.

41. Stergiopoulos, T.; Arabatzis, I.M.; Katsaros, G.; Falaras, P.; Nanoletters 2002, 2, 1259.

42. Nogueira, A.F.; De Paoli, M.-A.; Sol. Energy Mater. Sol. Cells 2000, 61, 135.

43. Nogueira, A.F.; Durrant, J.R., De Paoli, M.-A.; Adv. Mater. 2001, 13, 826; Nogueira, A.F.; De Paoli, M.-A.; Montanari, I.; Monkhouse, R.; Nelson, J.; Durrant, J.R.; J. Phys. Chem. B 2001, 105, 7517.

44. Katsaros, G.; Stergiopoulos, T.; Arabatzis, I.M.; Papadokostaki, K.G.; Falaras, P.; J. Photochem. Photobiol. A: Chem. 2002, 149, 191.

45. Stathatos, E.; Lianos, P.; Krontiras, C.; J. Phys. Chem. B 2001, 105, 3486.

46. Ren, Y.; Zhang, Z.; Fang, S.; Yang, M.; Cai; S.; Sol. Energy Mater. Sol. Cells 2001, 71, 253; Ren, Y.; Zhang, Z.; Fang, S.; Yang, M.; Cai, S.; J. Appl. Electrochem. 2001, 31, 445.

47. Cao, F.; Oskam, G.; Searson, P.C.; J. Phys. Chem. 1995, 99 , 17071; Tennakone, K.; Senadeera, G.K.R.; Perera, V.P.S.; Kottegoda, I.R.M.; De Silva, L.A.A.; Chem. Mater. 1999, 11, 2474; Matsumoto, H.; Matsuda, T.; Tsuda, T.; Hagiwara, R.; Ito, Y.; Miyazaki, Y.; Chem. Lett. 2001, 26.

48. Kubo, W.; Murakoshi, K.; Kitamura, T.; Wada, Y.; Hanabusa, K.; Shirai, H.; Yanagida, S.; Chem. Lett. 1998, 1241; Murai, S.; Mikoshiba, S.; Sumino, H.; Hayase, S.; J. Photochem. Photobiol. A: Chem. 2002, 148, 33.

49. Papageorgiou, N.; Maier, W.F.; Grätzel, M.; J. Electrochem. Soc. 1997, 144, 876.

50. Cowie; J.M.G.; Cree, S.H.; Ann. Rev. Phys. Chem. 1989, 40, 85; Armand, M.; Adv. Mater. 1990, 2, 278.

51. De Paoli, M.A.; Gazotti, W.A.; J. Braz. Chem. Soc.2002, 13, 410.

52. Nogueira, A.F.; Spinacé, M.A.; Gazotti, W.A; Girotto, E.M.; De Paoli, M.-A.; Solid State Ionics 2001, 140, 327.

Received: March 25, 2003

Published on the web: December 4, 2003

FAPESP helped in meeting the publication costs of this article. 